2008-12-01

\title{
Growing through Copying: The Negative Consequences of Innovation on Franchise Network Growth
}

Robert J. Jensen

robertjensen@byu.edu

Gabriel Szulanski

Follow this and additional works at: https://scholarsarchive.byu.edu/facpub

Part of the Business Administration, Management, and Operations Commons

\section{Original Publication Citation}

Szulanski, G., Jensen, R.J. 28. Replication, Copy Exactly, and the Growth of Franchising Networks: The Negative Consequences of Franchising Innovation. Research Policy 37 (1): 1732-1741. http://www.journals.elsevier.com/research-policy/\#description

\section{BYU ScholarsArchive Citation}

Jensen, Robert J. and Szulanski, Gabriel, "Growing through Copying: The Negative Consequences of Innovation on Franchise Network Growth" (2008). Faculty Publications. 920.

https://scholarsarchive.byu.edu/facpub/920 


\title{
Growing through Copying: The Negative Consequences of Innovation on Franchise Network Growth
}

\author{
${\text { Gabriel Szulanski }{ }^{\text {a,* }} \text {, Robert J. Jensen }}^{\text {b }}$ \\ a INSEAD, Ayer Rajah Avenue 138676 Singapore, e-mail: Gabriel.szulanski@insead.edu, Tel: (65) 6799 \\ 5388, Fax: (65) 67995399 \\ b Marriott School, Brigham Young University, 783 TNRB, Provo, UT 84602, USA, ,e-mail: \\ robertjensen@byu.edu,Tel: (801) 422-4413,Fax: (801) 422-0540 \\ * Corresponding Author
}

\begin{abstract}
We explore how copying more exactly a blueprint for establishing a franchise network in a new country influences franchising network growth. We test opposing hypotheses using panel data involving the transfer of franchising knowledge to 23 different countries, measuring the degree to which master licensees "copy exactly" knowledge concerning how to grow a network in their country and the effect that their approach has on subsequent network growth. We conclude that a strategy of copying more exactly seems to enhance growth and that the benefits of more exactly replicating knowledge in the first year of a local network's existence persist for several years. Thus, innovation, in this specific context, seems to hinder firm growth.
\end{abstract}

Keywords: Replication, Knowledge transfer, Franchising, Copy Exactly, Growth 


\section{Introduction}

Since Schumpeter (1911), sustained and comparatively faster innovative activity has often been considered to be a strong correlate to firm growth (Del Monte and Papagni, 2003). More recently, however, the replication, or exploitation, of an innovative business model has also become an increasingly salient driver of firm growth. Indeed, the successful geographic replication of a business model is the primary form of growth strategy for a diverse and increasingly large set of organizations that grows through the creation and operation of a large number of similar outlets that deliver a product or perform a service.

These "replicator" organizations, which focus on growth through exploitation rather than continuous innovation are emerging in many sectors as a dominant economic phenomenon of our time. In 1997, 62\% of all retail sales in the United States passed through chain organizations and their share of economic activity is rising (Kalnins and Mayer, 2004). Chains are now active in over 75 industries as diverse as fast food, banking, discount retailing, hotels, accounting, mail service, interior design, and personnel consulting. By 2001, business format franchise chains alone had created 14 percent of all private-sector jobs and 11 percent of all private-sector payroll in the United States (Association, 2004).

Conventional wisdom suggests that the replicator's 'formula' for success is either sufficiently simple or well understood that it can be tailored uneventfully to fit the relevant characteristics of the host environment through adaptive modifications. ${ }^{1}$ Few

\footnotetext{
${ }^{1}$ Innovation is defined as introducing a new method of doing business. Adaptation to a new environment of a set of business practices comprised in a franchise system is, by definition, innovation in as much as it introduces a new way of doing things in that environment which is also different from the standardized, replicated franchise model. In this study we use the term innovation to describe modifications made to
} 
challenge that such innovations are to some degree necessary to fit new environments if performance is to be maximally effective, especially when contexts vary widely, such as in the case of international expansion. Indeed, previous work in the International Business literature has suggested that such local adaptation may be essential to successful subsidiary operation (e.g. Bartlett and Ghoshal, 1989; Kostova, 1999) and possibly for subsidiary survival (Sorge, 1991).

Closer scrutiny of how replicator organizations grow, however, has uncovered possible disfunctions of adaptive innovations. It is increasingly recognized that the business model or system leveraged by a replicator is often a complex set of interdependent activities (Porter, 1996; Rivkin, 2001; Winter, 1987). Reproducing such a "recipe" often means recreating the knowledge underpinning a system of complex, causally ambiguous, and imperfectly understood productive processes at each new site.

Thus, an emerging view contends that the nature of the knowledge to be replicated is an important factor affecting the relationship between local innovation and performance (Baden-Fuller and Winter, 2006; Winter and Szulanski, 2001) which is at least as important as knowledge of the local environment. Thus, knowledge for subsidiary success is no longer seem to reside mostly at the local level but may be embedded in headquarters and thus shifts the balance point between center and local knowledge at least early in a unit's life. Innovation in the form of local adaptation, if undertaken too early or too substantially may undermine the ability to utilize the template, or original set of practices thus hampering the replication (Jensen and Szulanski, 2007; Szulanski and 
Jensen, 2006). In such circumstances, a strategy of discouraging innovation and copying the original as closely as possible has been found to be efficacious.

This paper addresses two primary questions. First, to what extent is such strategy of "copying more exactly" efficacious in the cross-border transfer of knowledge? Second, if such a positive effect exists, how persistent is it? Exact adherence to an original template becomes less needed as knowledge is better understood and local innovations can be made more effectively.

Our setting is the transfer of franchising knowledge from the headquarters of Mail Boxes Etc., a large, U.S. based non-food multinational franchise firm to 23 of its foreign subsidiaries. The period of observation is from 1989, with the opening of MBE's first international network, to 2003. Specifically, we measure the correlation between the degree to which Master Licensees (MLs - individuals who own the right to build a network in a country or region) follow a codified blueprint for network growth and the ensuing growth of their franchising networks. The analysis suggests a strong positive correlation between growth and how closely the blueprint is followed, implying a negative correlation between ML innovation, and growth, an effect that persists for the first several years of a network's existence.

\section{Theoretical background and hypotheses}

\subsection{Replication of organizational routines}

While many types of knowledge assets may be important for gaining and sustaining competitive advantage, Teece, et al. (1997), following Nelson and Winter (1982), suggest that, due to causal ambiguity and inherent difficulty in imitating them, those most clearly contributing are embedded in organizational routines (see also Jensen 
and Szulanski, 2007; Rivkin, 2001; Winter, 1995). While possession of superior routines, i.e.; those that produce superior performance, is a necessary condition for sustained competitive advantage it likely is not sufficient for most firms. Superior routines are often a product of a particular time and place, developed in relation to specific circumstances and personnel (Amit and Schoemaker, 1993). As such, they tend to originate in specific locations and require transfer, or replication, to other locations in order to exploit their value (Winter and Szulanski, 2001). While there is some cost to transfer, however, the value of successful practices is often maximized by transferring them to as many relevant units as possible within the organization.

Given that organizational routines embody a firm's productive knowledge, unless an MNC competes solely through exports, competitive advantage on a global scale may require the replication of successful practices. Indeed, replication is increasingly recognized in the strategy literature as a fundamental source of competitive advantage (Argote and Ingram, 2000; Bradach, 1998; Jensen and Szulanski, 2007; Kostova, 1999; Rivkin, 2001; Szulanski and Jensen, 2006; Teece, et al., 1997; Winter, 1987; Winter, 1995; Winter and Szulanski, 2001) and scholars in International Business have long suggested that the value of leveraging superior organizational practices through replication in different countries is a fundamental reason for MNC existence (Buckley and Casson, 1976; Hymer, 1976; Kogut and Zander, 1993; Zaheer, 1995). This is particularly true for multinational franchises which compete primarily through the replication of successful practices.

\subsection{Necessity of local innovation in cross-border replication: the potential negative} consequences of copy exactly 
One of the fundamental questions for organizations pursuing growth through replication is whether or not and to what extent they need to innovate by adapting transferred knowledge to fit varied local environments. Innovation and adaptation are synonymous in this regard as both engender changes to the established model. The general economic argument is that profit maximization in the presence of market heterogeneity necessitates local innovation. Geographic dispersion exposes replicating organizations to diverse market conditions. Thus, uniform operating procedures cannot optimize performance in each location (Kaufmann and Eroglu, 1999). Indeed, franchising as an organizational form is often considered to represent an efficient response to the need for local innovation as franchisees operate with the clear objective to maximize their own, local profits (Alchian and Demsetz, 1972; Brickley and Dark, 1987). Moreover, local units have the most relevant knowledge of prevailing local tastes and market conditions which should presumably enhance the odds of success of any innovation they introduce to the replicating organization's standardized practices (Minkler, 1992).

This is particularly true for the replication of organizational practices across national borders. In general, it is argued that conditions vary widely in different locations, resulting in differential performance of standardized, transferred assets (e.g. Khanna and Rivkin, 2001; Westney, 1993; Yip, 1991) creating pressure for innovation as firms attempt to maximize their fit with the local environment (Bartlett and Ghoshal, 1989; Nohria and Ghoshal, 1997). These pressures take the form of basic differences in culture (Hannon, et al., 1995; Lemak and Arunthanes, 1997), governmental regulations (Kostova and Roth, 2002), labor practices (Rosenzweig and Nohria, 1994), and consumer 
preferences and needs (Bartlett and Ghoshal, 1989; Prahalad and Doz, 1987), particularly in service industries where most replicator organizations operate.

Indeed, the role and effect of innovation is one of the most frequently discussed topics in the literature on transferring assets across borders (Bartlett and Ghoshal, 1989; Kostova, 1999; Prahalad and Doz, 1987), with significant agreement in the general literature, as well as in the literature focusing specifically on organizational practices, that some level of innovation is necessary to ensure both the performance and long term survival of a subsidiary (Bartlett and Ghoshal, 1989; Luo, 2000; Morosini, et al., 1998; Sorge, 1991). If innovation, as conventional wisdom and much of the literature argues, is necessary for the transferred knowledge to fit local environmental characteristics one would expect a policy of copy exactly to result in poor fit and hence, in poorer performance.

H1. In replicator organizations, a policy where knowledge is copied more exactly will decrease sub-unit performance.

\subsection{Templates and the positive consequences of copy exactly}

It is not obvious, however, that attempts at modifying a proven model will end up being a success. Even knowledge embedded in franchising practices, which many consider to be relatively simple (Knott, 2001), is likely to be at least moderately complex and contain elements of causal ambiguity (Lippman and Rumelt, 1982; Rivkin, 2000). Even when local contexts are dissimilar, the benefits of local innovation may well be outweighed by the risks associated with the modification of complex, causally ambiguous knowledge (Winter and Szulanski, 2001). Indeed, local innovation assumes that (1) the local environment is understood adequately, (2) that the knowledge contained in the original practice, or template, is equally well understood, and that (3) local actors, are 
fully cognizant of the potential interactions between the relevant features of the environment and the new practices.

In practice, local actors often do not know their local environment as well as expected (Westney, 1987), the knowledge contained in the template is more complex and causally ambiguous than anticipated (Jensen and Szulanski, 2007; Szulanski and Jensen, 2006) and local actors, not having implemented the knowledge before, are unaware of potential interactions between the knowledge and the local environment (Leonard-Barton, 1988). Given these constraints, a new view on replication is emerging that emphasizes accurate, template-based replication that refrains from modifying proven knowledge and systems (Winter and Szulanski, 2001).

The difficulty with innovation under such circumstances is that it reduces the value of the knowledge contained in the original, or template, practice (Jensen and Szulanski, 2007). When copied more exactly, the original can serve as a reference for diagnosing and solving problems that arise during transfer and implementation (Winter and Szulanski, 2001). Innovation abandons the original template resulting in the necessity of learning by doing rather than learning from others. The result may be decreased performance, at least initially.

When problems occur during implementation a policy of copying as exactly as possible may aid in determining not only if faulty implementation is the cause of initial problems but also in determining the degree to which problems arise from local differences. Assuming that the template is applied in multiple locations, a policy of copying as exactly as possible is more likely to maintain conformity with the broader network of units that have implemented the knowledge, a network that has already dealt with a variety of local issues when implementing a standardized set of organizational routines. The experience from the broader network may thus aid in 1) determining if problems are associated with faulty implementation or with local differences and 2) 
managing local differences during implementation. Innovation decreases the usefulness of not only the original but the broader network as well potentially leading to greater implementation problems and lower performance.

H2. In replicator organizations, a policy where knowledge is copied more exactly will increase sub-unit performance.

If there is a positive effect for copying transferred knowledge more exactly, one would expect a copy exactly policy to exhibit diminishing returns over time.

Specifically, such a policy is likely to be of most use when the transferred knowledge is not well understood, at the beginning of a unit's life when the knowledge is new. Over time one can expect the management of the local network to more clearly understand the practices and be able to modify them sensibly thus improving overall performance without destroying its underlying value, allowing the local unit to focus on innovating within the local environment without decreasing network growth.

H3. In replicator organizations, the benefits of copying knowledge more exactly decrease over time.

\section{Data, Measures and Methods}

\subsection{Setting}

\subsubsection{Franchising}

The general empirical setting for our study is franchising. Franchise organizations provide a natural laboratory for the study of replication (Nelson and Winter, 1982) as they compete primarily through the creation and operation of a large number of very similar outlets according to a uniform business model. The cloning of a common system of practices in geographically dispersed units is the very essence of what a franchise 
chain does (Bradach, 1998). Franchises tend to dominate service industries where direct contact with the individual end consumers is necessary. As a consequence, they are subject to strong pressures for local innovation. Moreover, franchise organizations operate across an arms-length interface with their franchisees. They cannot completely enforce how these franchisees receive and utilize the knowledge being transferred (Bradach, 1998; Kaufmann and Eroglu, 1999). Enforcement is even less likely between franchisors and Master Licensees (MLs), the people who purchase the right to develop a network for an exclusive geographic territory, because deviations from the type of knowledge transferred to MLs are often more tacit and less critical for the identity of the brand. This allows for greater variation in local innovation decisions than one might find in company-owned stores or subsidiaries where firms can resort to hierarchical authority and fiat to enforce compliance with a particular set of practices.

\subsubsection{Mail Boxes Etc.}

The specific setting of our study is Mail Boxes Etc. (MBE), which is the largest non-food franchise in the world. We examine the growth of MBE networks in 23 different countries. MBE was founded in 1980 in San Diego, California in an effort to meet needs unfulfilled by the postal service. MBE specializes primarily in services for the Small Office and Home Office (SOHO) environments, including photocopying, color copying, packing and shipping, parcel and express courier, complete mailbox service, Internet access, and office and packing supplies. In 1986, when it went public, MBE had grown to 250 franchise outlets. Four years later, in 1990, it had grown to over 1000 centers, and, by 1999, had quadrupled again to nearly 4000. After securing a strong foothold in the United States and building a foundation of experience, MBE decided, in 
1989, to sell master franchise licenses abroad. By 1999 MBE was operating over 700 international outlets. This paper will focus exclusively on the transfer of knowledge concerning the task of building a global MBE network.

\subsection{Data Collection}

Data sources include archival data, a detailed survey of most of the MLs of the country networks studied which we repeated for three consecutive years, and interviews of senior management at MBE headquarters, in particular those in charge of global expansions, and with each of the MLs. In all cases the interviews were semi-structured and aimed at uncovering the role of the ML, the replication process, and the difficulties of expanding a franchise network overseas, specifically focusing on the balance between following the approach recommended by headquarters for developing a network versus creating one that is supposedly adapted to local needs. The archival data covers the period from 1989 which marks the beginning of MBE's international expansion, through 2003. Ultimately yearly observations of 23 national networks are included in the data set for a total of 183 observations. The interviews took place between 1999 and 2003. Finally, the survey was administered in 2001, 2002, and 2003. To minimize observer effects, we refrained from offering opinions or suggestions to the participants until the study was completed. Sections 3.3. and 3.4. detail how we've measured the degree to which the transferred knowledge was copied exactly and the growth of the network. The dependent variable was extracted from the archival data while the independent variables were obtained from the survey and verified by interviews. Data for control variables stems mostly from publicly available data.

\subsection{Dependent variable: network growth}


Performance in early-stage franchise organizations is best reflected by the number of franchises sold and stores opened (Bradach, 1998; Love, 1995). Same store sales growth is generally not used as a measure of growth until the network reaches a stable size and growth in the number of stores slows down significantly or abates. We measured growth through each network's entire existence although we ultimately focused on growth in the first decade when growth in the number of stores is most critical for the establishment of the national network.

The growth in the number of franchises is a key measure of ML performance because it provides a vital revenue stream of franchise fee payments from the sale of new franchise units. That revenue, in turn, funds the development of the ML's central infrastructure that is necessary to support the growing network of stores until royalty payments from those centers are sufficiently substantial (Bradach, 1998). Network growth is not only used by academics to measure early franchise performance, but is also one of the primary performance metrics both at $\mathrm{MBE}$ and in other franchising organizations (Bradach, 1998). Growth was measured as the number of franchises sold by the end of each calendar year and was determined using archival data.

\subsection{Independent variable: copying more exactly}

We operationalized the degree to which a unit copies knowledge as the degree of ML conformity to the standard MBE approach to building a network. We established conformity primarily through quantitative indicators of ML network building activities derived from the surveys reinforced with qualitative indicators derived from the interviews measuring the perception of having conformed and/or the intention to conform. The measure consists of the number of departures made by the ML from the 
bluepring for network growth. We wish to point out that these are not deviations from the franchise formula made by individual franchisees. The blueprint for network growth is different from the franchise business format for individual stores.

The quantitative measure was arrived at by enumerating the network building practices included in the blueprint and determining the percentage of practices that were actually implemented by the Master Licensee (see Szulanski and Jensen, 2006; Westphal, et al., 1997 for further details and discussion of such measure). We utilized a cutoff point of one calendar year to determine whether a deviation has occurred. A year is a natural period because it is the period covered by the blueprint, and it is long enough to determine the vector of actions chosen and implemented by the ML but not long enough for the performance consequences of those actions to fully reveal themselves and trigger corrective action.

Concerning how to develop an MBE network, MBE Headquarters codifies recommendations to MLs concerning seven specific domains of activity, (1) marketing the MBE franchise, (2) selling the MBE franchise, (3) training the franchisees, (4) selecting sites, (5) designing and constructing MBE centers, (6) supporting the franchisee, and (7) developing infrastructure. The seven domains can be considered "core" in the sense that nearly all potential elements of the system for network growth are related to them (Hannan, et al., 1996; Siggelkow, 2002) and they have a sizeable impact on the shape of future organizational elements (Baron, et al., 1999).

The instructions for the seven domains are organized in the form of a timeline known internally as the "52-week plan" that pertains to the initial year of the growth of a 
network. $^{2}$ The 52 -week plan lists 330-335 actions, the number of actions depending on whether the ML uses an area structure, to be taken by an ML, specifying their timing on a week by week basis. It is the number of specific actions out of 330/335 in the 52-week plan followed by the ML that constitute the percentage mentioned in establishing conformity with the standard approach. Except in one case where we had detailed information for every activity, we estimate the range of possible actions taken by the master licensee. Even for those who had recently finished the first year of operations it was impossible to infer the exact number of steps taken out of 335 . In order to ensure conservative results we utilized the archival and interview data to construct a lower and upper bound to the number of steps taken. In the worst cases the range is 80 actions with the average range being 40 actions out of 335 . We analyzed the data utilizing the minimum, maximum, and the mid-point in the potential number of actions taken. ${ }^{3}$

It should be noted that the information contained in the 52-week plan, while codified, was somewhat ambiguous and relatively complex. The information represented a compilation of dozens of lessons learned through the building of the U.S. and other international networks. When specific problems were encountered, the solution to those problems was incorporated as a task in the 52-week plan. For instance, experience revealed that it was desirable to defer some types of advertising until after the sixth week of network operation. Causal explanations of how those moves impacted growth were not, however, codified into the 52-week plan. Furthermore, the implications of

\footnotetext{
${ }^{2}$ Our confidentiality agreement prevents us from revealing exact details of the 52-week plan.

${ }^{3}$ As there were no statistically significant differences in the effect we report only the results of the analysis done using the mid-point.
} 
advertising from day one or delaying it by six weeks were addressed haphazardly, if at all. Such knowledge, instead of being codified, was transferred predominantly through personal communication between MLs. Furthermore, the interrelationship between various parts of the 52-week plan and the plan's applicability to different environments was unknown, even by headquarters. The 52-week plan represented codified local learning and no one had systematically mapped out the implications of altering or abandoning parts of the plan. While such learning was partially available in the larger MBE international network, again, it was only transferred unsystematically via personal communication between MLs.

\subsection{Control variables}

In order to control for other factors that might affect network growth we include (1) year dummy variables, (2) the time varying population, (3) the time varying GDP per capita to control for consumer purchasing power, (4) the time varying degree of population density, (5) adaptation in terms of both changes to the existing routines and the addition of new routines to the business format (measured as the Euclidean distance between the headquarters' recommended product mix and the product mix for the average store within each country and the percent of revenue generated by the sale of non-standard firm products (those introduced by the franchisees and not sanctioned by the firm) for the average store within each country) to control for variation in the nature of the business format (non-time varying), ${ }^{4}(6)$ the cultural distance between the country and the U.S., the origin of the replicated knowledge. The cultural distance measure follows Kogut and Singh (1988) and was derived from Hofstede's indices (1980). For

\footnotetext{
${ }^{4}$ The adaptation measures were obtained through the repeated survey with the Master Licensees. The measure is non-time varying being either the only response available or the response average and is assumed to be similar across all years in the sample.
} 
cultural distance we include the interaction term as well in case it moderates the primary relationship, and (7) the square of the copy more exactly variable to control for the possibility that the relationship is convex curvilinear, or inverted $U$ shaped, indicating that moderate degrees of innovation are most appropriate rather than copying as exactly as possible.

\section{Findings}

Table 1 provides the descriptive statistics and correlations using, for the measure of Copy More Exactly, the mid-point between the minimum and maximum number of actions taken in accordance with the 52 week plan.

Insert Table 1 Here

We tested the hypotheses using the Baltagi-Wu estimator embedded in the Stata xtregar command, which allows for modeling unbalanced panel data with an AR(1) data structure. We utilized random effects in estimating the models because fixed effects panel data estimation does not allow for non-time-varying predictors. The specification is as follows:

$$
\begin{aligned}
& Y_{i t}=\alpha+X_{i t} \beta+v i+\varepsilon_{i t} \\
& \varepsilon_{i t}=\rho \varepsilon_{i}+\eta_{i t}
\end{aligned}
$$

where $X$ is a vector of control and predictor variables and $i=1, \ldots, N ; t=1, \ldots, T_{i} ;|\rho|<1, \eta_{i t} \sim \operatorname{iid}\left(0, \sigma^{2}{ }_{\eta}\right)$, and $v_{i} \sim \operatorname{iid}\left(0, \sigma^{2}{ }_{v}\right)$

We estimated a series of models. First, utilizing the full dataset which includes the entire lifespan of all networks to 2003, we estimated a set of models with only the control 
variables, except for the cultural distance/copy more exactly interaction which is included in model 3 and the copy more exactly squared term which is included in model 4. Due to the low number of observations none of the control variables were significant when all were simultaneously included in the model. We then utilized a stepwise procedure removing the year dummy variables first and then the least significant control variables one by one. In the final analysis, cultural distance was the only control variable with statistical significance. Model 2, testing hypotheses 1 and 2, also utilizing the entire dataset, added the Copy More Exactly measure. Model 3 included the interaction between Cultural Distance and Copy More Exactly while model 4 removed the interaction and included the Copy More Exactly squared term. Table 2 includes models 1 through 4. Models 5 through 12, testing the sensitivity of the first two hypotheses and testing hypothesis 3 , are reported in Table 3. These models track the effect of Copying More Exactly and Cultural Distance across different unit ages beginning with the effect through the $2^{\text {nd }}$ year of the networks' existences up to the $9^{\text {th }}$ year. These models do not include the Cultural Distance/Copy More Exactly interaction term nor the Copy More Exactly squared term as these were not significant in the overall model and degrees of freedom are limited in these models as they restrict the dataset to only appropriate networks and years. As an example, for model 3 we include all networks as all were in existence at least 2 years in 2003 but only include the first two years of each network's growth. For model 10 we include only those networks with at least 9 years of growth capping it at year 9 .

Insert Table 2 Here 
Insert Table 3 Here

Hypothesis 1 predicts a negative relationship between copying more exactly and network growth. In both tables, comprising models $2-12$, the coefficients on copy exactly are positive ( $B=0.140$, not significant) indicating that $\mathrm{H} 1$ is not supported.

Hypothesis 2 predicts a positive relationship between copying more exactly and network growth. The results from Table 1 , model 2 , are not significant ( $B=0.140$, not significant) suggesting, initially, little support for $\mathrm{H} 2$. When the interaction between Cultural Distance and Copy More Exactly is included (model 3) the direct effect of Copy More Exactly is marginally significant, although the interaction term is subsequently left out of further modeling due to the insignificance of that measure. However, the lack of significance is to be expected as decisions made at the beginning of a unit's life are likely to become less significant over time as other events occur and other effects become more salient. This is illustrated in Table 3, models 5-12 (year 2: $B=0.030, p<0.001$ to year 8: $B=0.170, p<0.10)$. When estimated by age of network the coefficients are positive and significant through year eight of a network's existence, indicating support for $\mathrm{H} 2$ at least through the initial years of network growth.

Hypothesis 3 predicts a diminishing effect of copy exactly over time. In contradiction, the coefficients in Table 3 increase over time. The significance of the coefficients, however, as hypothesized, diminishes over time as the local culture has an increasingly salient effect on network growth (year 2: $B=0.030, p<0.001$; year 8: $B=0.170, p<0.10$; 
year 9: $B=0.173$, not significant). This suggests that decisions made at the beginning of a network's life concerning transferred knowledge have a large immediate impact that persists and even grows stronger - much like laying the foundation on which to build a building, but that, over time, local effects play an increasing role in determining how fast a network grows. This indicates support for $\mathrm{H} 3$.

In sum, we did not find support for hypothesis 1, but did find support for hypotheses 2 and 3. We find a significant positive effect of copying more exactly and, inversely, a significant negative effect of local innovation. However, while this effect strengthens over time it becomes less statistically significant, potentially as a result of the increasing effect of local culture.

\section{General discussion and conclusion}

Innovation is often seen as a central driver of growth in open economies. Since Schumpeter, it has been argued to be an essential element of growth in most industries with firms either constantly innovating or succumbing to the gales of creative destruction (Schumpeter, 1911). Even a short survey of current research in a number of fields indicates that innovation is one of the most often researched subjects with hundreds of books and articles published on the topic each year. Yet, despite decades of arguments suggesting that innovation in terms of developing new ways of doing business to fit local environments is critical to the growth of subsidiaries of multinational organizations (Bartlett and Ghoshal, 1989; Kostova, 1999), our analysis reports a strong negative correlation between innovation and network growth. Indeed, much of the growth observed in our data happens through the purposeful suppression of innovation. 
In this sample, as with many MNCs, knowledge is out of balance. Both headquarters and subsidiaries possess relevant knowledge necessary for firm and subsidiary success. While conventional wisdom suggests that the local knowledge is more critical for subsidiary success, our findings suggest that the knowledge transferred by headquarters may be more valuable, at least at first, with innovation causing potentially the abandonment of the very knowledge which made the franchise successful in the first place. Under such conditions, despite the need for local innovation, replicating knowledge as closely as possible may be sensible.

Part of the findings may be due to the commonsense observation that growth often requires more than just the initial innovation -- it requires exploitation as well in order to maximize value (McNamara and Baden-Fuller, 2007). This is likely to be particularly true in a knowledge economy as critical innovations may occur in locally developed processes and practices where the innovation is embedded in organizational routines. Replication is a primary mechanism for exploiting these types of innovations (Winter and Szulanski, 2001) and is a central part of the business model pursued by the firm in this study. As a consequence, one would expect replication to at least increase the return the firm obtains on its original innovation. This does not, however, adequately address the question of why growth is depressed by local innovations and why a policy of copying more exactly increases the rate of network growth.

At least a portion of the findings may be the result of a more complicated interaction between replication and innovation. Instead of involving only exploitation, replication may play a role in the process of innovation (Gilsing and Nooteboom, 2006). To begin with, however, we need to delineate a few characteristics of innovation, 
including that innovation which involves creating new business practices by adapting a standardized model to a local environment. First, innovative skills are not distributed equally throughout the population. This hints at a possible role, which we discuss below, for replication within the process of innovation. As a result of unequal distribution, if we take a random sample of individuals they are likely to have different experiences attempting to innovate. Some will quickly be able to innovate successfully, the majority will require significant time, effort, and trial and error learning, while others will likely be unable to innovate at all.

Second, this scenario is compounded if we consider innovating within a current organizational form or within a specific firm (the type of innovation specific to local adaptation), particularly if the innovation occurs without significant experience with either. Indeed, Adner and Levinthal (2001) have suggested that while the entrepreneur is critical, an understanding of the environment in which the innovation takes place also plays a large role in understanding innovation. For instance, suppose you ask a random sample of individuals with little to no experience running fast food restaurants to innovate within that organizational form. There are four possible outcomes. First, they may innovate unsuccessfully. Given the degree to which most new businesses fail this is probably the most likely outcome. Second, they may spend time, money, and effort developing knowledge which already exists, but of which they are currently unaware. Third, they may develop innovations which appear successful at first but which lower potential profitability as they undermine the economic logic of the organizational form or, if the innovation occurs within an existing firm, interrupt the interrelationship between productive subroutines of the existing, successful, business model. Finally, they may 
develop successful innovations which are both novel and relevant to the existing business model and/or organizational form.

Replication, because it involves the re-creation of a successful model within an existing organizational form, may reduce the incidence of the first three outcomes. Indeed, a policy of copying more exactly for a period of time is likely to suppress improper innovations, enhancing the possibility of successful ones. In this regard replication is not just a tool for leveraging existing innovations but a method for lowering the risk and effort of innovation by allowing one to master the existing form first. In other fields, such as art and architecture, a common observation is that successful innovations tend to come from those who have first mastered existing techniques. Those who are successfully able to break the rules, to innovate, are those who are masters of existing practices. Similar to studying art from a master painter, replication may lower the threshold for successful innovation by providing a proven route to mastery within the organizational form being replicated. In this respect, our findings contribute to the literature on innovation by not only empirically verifying the observation that innovation requires exploitation in order to maximize its value but suggest as well that the very process of initial innovation may be enhanced by exploitation through close replication.

Anecdotal data from interviews with MBE's master licensees (MLs) illustrates this concept, both the dangers of innovating without mastery and the benefits of doing so once mastery is attained. First, illustrating the dangers: despite the successful German ML requiring a policy of copy exactly the Austrian ML indicated in interviews that the Austrian market was different from the U.S. and that he did not think the unit level MBE model could be implemented without innovation. As a consequence, he encouraged his 
franchisees to innovate, deviating from the existing business model by deemphasizing the primary profit centers within the business and elevating others. Because he had not mastered the existing model he did not appear to understand the underlying economic logic of the business. He felt that the innovation required him to recruit more educated, sophisticated franchisees who, in turn, demanded higher returns on their investment. Because his innovation, on average, did not support those higher returns, the pool of potential franchisees decreased and growth was slow.

The Canadian ML allowed a very similar, if not identical, innovation, deemphasizing the primary profit centers and emphasizing the same ones as the Austrian ML. He too felt that the U.S. model was not optimized for Canada. However, unlike the Austrian ML, the Canadian ML chose to pursue a period of copy exactly concerning franchisee operation of the business model for four years after launching his network.

"I said 'hey, this [the original MBE model] is a pretty successful concept,' and I still believe it is probably one of the most successful, if not the most successful, service concepts in the world. ... So, [concerning modifications] I went kind of slow to start with." - Canadian $M L$

By the end of the four year period he felt that he understood the underlying logic of the business model and how to effectively alter it without destroying the reasons for its success. His assessment appears to have been correct as the Canadian network is the second largest in MBE and he was able to innovate without removing his existing franchisees or undermining the return on investment that franchisees received. This case suggests that mastery enabled successful innovation.

Replication, then, is involved in leveraging prior innovations and in lowering the threshold required for new innovation by enabling mastery of existing practices. In addition, it may enable innovation more directly through the replication of skills required 
for innovation. Music schools that teach improvisation and Business schools that teach classes in entrepreneurship are both examples of attempts to replicate creative skills. To the extent that firms train the owners and managers of replicated units in the skills necessary to successfully innovate, replication may further lower the time, effort, and risk required to create value through innovation.

\section{Managerial Implications}

This study has clear managerial implications. First, it suggests that franchisors who operate a Master Licensee system should control the incidence of innovation among MLs. This is an important point as one of the primary reasons for using MLs is to accelerate growth by delegating network growth activities and decisions that rely heavily on local knowledge. Despite the possession of local knowledge and pressure from the local environment, the study indicates that discouraging innovation for a period of time is beneficial not just to the firm as a whole but to the individual ML as well. Ancillary to this is the need for franchise firms to more fully understand the knowledge that is transferred and be able to ascertain mastery. While knowledge on unit operations is often highly codified and understood, knowledge of how to build a successful network is often less codified. To the extent that the knowledge is codified and causal ambiguity is low, firms may be able to shorten the period of copy exactly and successfully allow innovation at an earlier time.

\section{Limitations and future directions}

Our work is limited by several considerations. First, event though it involved 23 different countries, it occurred within a single franchise firm. We believe that MBE is suitable as a research setting for a number of reasons, including (1) similarity in 
operations and growth patterns to a variety of other replicator organizations; (2) relative age- old enough to have established itself and yet young enough to be continuing growth with the same model and structure over the entire period of observation; (3) size-large enough to ensure a sufficient number of units for the study; and (4) the availability of data over an extended period of time. However, it still involves only a single firm and one should be cautious in applying the findings to firms in other industries and to nonfranchise firms.

In particular, while we believe that the theoretical foundation of this paper applies to a broader set of MNCs beyond multinational franchising, the findings should be generalized with caution. However, one might expect the findings to be least applicable in multinational franchising where the retail service nature of most franchisors requires close contact with the end consumer and a subsequent need for increased innovation in the form of local adaptation. Under such circumstances one would expect the effect of copying more exactly to be weaker, or perhaps even negative. A broader sample of MNCs may include subsidiaries which are part of a global supply chain or ones with customers that are also large MNCs rather than local actors embedded in a specific culture negating some of the need for innovation and increasing the positive effect of copying more exactly. Future research may contribute to the MNC literature, particularly the debates on standardization vs. local adaptation, by examining the effects of copy exactly on other types of MNC subsidiaries.

Our findings have implications for the future direction of research on knowledge management and knowledge sharing as well. A good portion of the current literature focuses on methods for increasing the number of weak ties in order to increase 
innovation. To the extent that our findings are generalizable they imply that greater research is needed instead on the process of identifying superior routines, the mechanisms of transfer, and methods for obtaining mastery in pursuit of innovation, i.e.; more research on the process and implications of replication as a strategy for growth. Focusing on creating and managing ties may be most appropriate for individual level knowledge management but less suitable for unit level knowledge sharing where replication processes generally occur.

We anticipate future work on replication and copying exactly in several areas. First, this study specifically involves copying more exactly knowledge of how to grow a franchise network. Future research may address whether copy exactly applies as well to the growth of specific units or stores, or the performance of other types of transferred knowledge assets. This would allow us to examine whether it applies equally to knowledge that is more codified and with which the firm has more experience (there are typically many more stores than networks within a franchise firm). Future research may also want to replicate the study in different contexts within a variety of industries including measuring its effect in non franchise firms. Third, future research may address the question of timing of innovation. While this research suggests that it should be delayed it does not address the optimal time to begin. As well, future research may address contingencies and moderating factors where it is applicable.

An exploration of the process of mastering an existing practice, how it occurs, and moderating factors that may address the speed of mastery is likely to be particularly valuable. In exploring the process of mastery, the construct of absorptive capacity may play a critical role (Cohen and Levinthal, 1990). Zahra and George (2002) outline four 
roles for absorptive capacity: acquisition, assimilation, transformation, and exploitation. While a policy of copy exactly clearly enables firms to harvest existing resources, an element of exploiting knowledge assets, such a policy may also enable better acquisition and assimilation as the intensive utilization of an existing template both narrows the scope of search in a transfer process to the existing practice, enables direct observation which increases the potential for making connections with existing recipient knowledge, and increases recipient comprehension of the transferred practice (Jensen and Szulanski, 2007). A policy of innovation, by abandoning the template, may decrease the speed at which absorptive capacity is increased, thereby decreasing unit performance. Future research should disentangle the specific effects of a policy of copy exactly on the absorptive capacity of the recipient unit as well as directly study the impact of template usage on both the speed and quality of developed absorptive capacity.

In summary, this study explores the effect of active suppression of innovation on network growth within a context of franchising, finding that a policy of copy exactly increases network growth. Competitive advantage in modern economies often requires the successful replication of knowledge so it can be exploited faster than it is imitated. Moreover, the number of firms that compete primarily through replication has increased dramatically. We hope that an understanding of the role of copying knowledge more exactly will invigorate an exploration of the dynamics of replication and aid in the management of replication initiatives and replicator firms. 
Table 1: Descriptive Statistics and Correlations

\begin{tabular}{|l|c|c|c|c|c|c|c|c|c|c|}
\hline Variable & Mean & St. Dev. & Min. & Max. & $\mathbf{1}$ & $\mathbf{2}$ & $\mathbf{3}$ & $\mathbf{4}$ & $\mathbf{5}$ & $\mathbf{6}$ \\
\hline $\begin{array}{l}\text { 1. Network } \\
\text { Growth }\end{array}$ & 36 & 68.8 & 0 & 408 & 1.00 & & & & & \\
\hline $\begin{array}{l}\text { 2. Avg. \# } \\
\text { Actions }\end{array}$ & 176 & 88.6 & 68 & 297 & .358 & 1.00 & & & & \\
\hline 3. Pop. & 42100000 & 30800000 & 2807110 & 128000000 & .07 & .26 & 1.00 & & & \\
\hline $\begin{array}{l}\text { 4. Per Cap } \\
\text { GDP }\end{array}$ & 13309 & 9559.7 & 891 & 42059 & .27 & .43 & .01 & 1.00 & & \\
\hline $\begin{array}{l}\text { 5. Pop. } \\
\text { Density }\end{array}$ & 128.2 & 116.1 & 2.3 & 474.22 & -.16 & .17 & .23 & .08 & 1.00 & \\
\hline $\begin{array}{l}\text { 6. Cultural } \\
\text { Dist. }\end{array}$ & 2.12 & 1.41 & .02 & 5.08 & -.41 & -.29 & -.07 & -.66 & -.03 & 1.00 \\
\hline
\end{tabular}

$\mathrm{N}=183$, italicized correlations are significant at the $\mathrm{p}<.05$ or better level

Table 2: Network Growth Regressed on Copy Exactly and Control Variables

\begin{tabular}{|c|c|c|c|c|}
\hline & Model 1 & Model 2 & Model 3 & Model 4 \\
\hline $\begin{array}{l}\text { Cultural } \\
\text { Distance }\end{array}$ & $-16.87^{* * *}$ & $-14.75^{*}$ & .753 & $-15.57 *$ \\
\hline Copy Exactly & & .140 & $.416^{\wedge}$ & .110 \\
\hline Interaction term & & & -.127 & \\
\hline Copy Exactly $^{2}$ & & & & .001 \\
\hline Overall $\mathbf{R}^{2}$ & .172 & .232 & .298 & .228 \\
\hline $\mathbf{N}$ & 183 & 183 & 183 & 183 \\
\hline
\end{tabular}

Table 3: Network Growth Regressed on Copy Exactly and Control Variables at Varying Network Ages

\begin{tabular}{|c|c|c|c|c|c|c|c|c|}
\hline & Mod.5 & Mod.6 & Mod.7 & Mod.8 & Mod.9 & Mod.10 & Mod.11 & Mod.12 \\
\hline & $2 \mathrm{yrs}$ & 3yrs & 4yrs & $5 y r s$ & 6yrs & $7 \mathrm{yrs}$ & $8 \mathrm{yrs}$ & 9yrs \\
\hline $\begin{array}{l}\text { Cult. } \\
\text { Dist. }\end{array}$ & -.287 & -.537 & -1.53 & -2.39 & -3.98 & -4.09 & -6.47 & -9.45 \\
\hline $\begin{array}{l}\text { Copy } \\
\text { Exact. }\end{array}$ & .030 **** & $.042 * * *$ & $.057 * *$ & $.071 *$ & $.091 *$ & $.148 *$ & $.170^{\wedge}$ & .173 \\
\hline $\mathbf{R}^{2}$ & .356 & .211 & .160 & .153 & .180 & .175 & .169 & .139 \\
\hline $\mathbf{N}$ & 46 & 63 & 80 & 95 & 102 & 98 & 112 & 99 \\
\hline
\end{tabular}




\section{References}

Adner, R. and Levinthal, D., 2001. Demand heterogeneity and technology evolution: Implications for product and process innovation. Management Science 47, 611628.

Alchian, A. and Demsetz, H., 1972. Production, information costs, and economic organization. American Economic Association 62, 777-795.

Amit, R. and Schoemaker, P.J.H., 1993. Strategic assets and organizational rent. Strategic Management Journal 14, 33-46.

Argote, L. and Ingram, P., 2000. Knowledge transfer: A basis for the competitive advantage of firms. Organizational Behavior and Human Decision Processes 82, $1-8$.

Association, I.F., 2004. Economic impact of franchising study nears completion. http://www.franchise.org/news/insider/030104.asp

Baden-Fuller, C. and Winter, S., 2007. Replicating knowledge practices: Principles or templates? Working paper: London, Cass Business School, City University

Baron, J.N., Hannan, M.T. and Burton, M.D., 1999. Building the iron cage: Determinants of managerial intensity in the early years of organizations. American Sociological Review 64, 527-547.

Bartlett, C.A. and Ghoshal, S., 1989. Managing Across Borders: The Transnational Solution. Harvard Business School Press, Boston, MA.

Bradach, J.L., 1998. Franchise Organizations. Harvard Business School Press, Boston.

Brickley, J.A. and Dark, F.H., 1987. The choice of organizational form: The case of franchising. Journal of Financial Economics 18, 401-420.

Buckley, P.J. and Casson, M.C., 1976. The Future of the Multinational Enterprise. MacMillan, London.

Cohen, W.M. and Levinthal, D., 1990. Absorptive capacity: A new perspective on learning and innovation. Administrative Science Quarterly 35, 128-152.

Del Monte, A. and Papagni, E., 2003. R\&D and the growth of firms: Empirical analysis of a panel of Italian firms. Research Policy 32, 1003-1014.

Gilsing, V. and Nooteboom, B., 2006. Exploration and exploitation in innovation systems: The case of pharmaceutical biotechnology. Research Policy 35, 1-23.

Hannan, M.T., Burton, M.D. and Baron, J.N., 1996. Inertia and change in the early years: Employment relations in young, high-technology firms. Industrial and Corporate Change 5, 503-536.

Hannon, J.M., Huang, I.C. and Jaw, B.S., 1995. International human resource strategy and its determinants: The case of subsidiaries in Taiwan. Journal of International Business Studies 26, 531-554.

Hofstede, G., 1980. Culture's Consequences: International Differences in Work-Related Values. Sage, Beverly Hills, CA.

Hymer, S.H., 1976. The International Operations of National Firms: A Study of Direct Investment. MIT Press, Cambridge, MA.

Jensen, R.J. and Szulanski, G., 2007. Templates and the effectiveness of knowledge transfer: An empirical investigation of the effects of templates and the mechanisms of template operation. Management Science, forthcoming 
Kalnins, A. and Mayer, K.J., 2004. Franchising, ownership, and experience: A study of pizza restaurant survival. Management Science 50, 1716-1728.

Kaufmann, P.J. and Eroglu, S., 1999. Standardization and adaptation in business format franchising. Journal of Business Venturing 14, 69-85.

Khanna, T. and Rivkin, J.W., 2001. Estimating the performance effects of business groups in emerging markets. Strategic Management Journal 22, 45-74.

Knott, A.M., 2001. The dynamic value of hierarchy. Management Science 47, 430-448.

Kogut, B. and Singh, H., 1988. The effect of national culture on the choice of entry mode. Journal of International Business Studies 19, 411-432.

Kogut, B. and Zander, U., 1993. Knowledge of the firm and the evolutionary theory of the multinational enterprise. Journal of International Business Studies 24, 625646.

Kostova, T., 1999. Transnational transfer of strategic organizational practices: A contextual perspective. Academy of Management Review 24, 308-324.

Kostova, T. and Roth, K., 2002. Adoption of an organizational practice by subsidiaries of multinational corporations: Institutional and relational effects. Academy of Management Journal 45, 215-233.

Lemak, D.J. and Arunthanes, W., 1997. Global business strategy: A contingency approach. Multinational Business Review 5, 26-37.

Leonard-Barton, D., 1988. Implementation as mutual adaptation of technology and organization. Research Policy 17, 251-267.

Leonard-Barton, D., 1995. Wellsprings of Knowledge: Building and Sustaining the Sources of Innovation. Harvard Business School Press, Boston, Massachusetts.

Lippman, S.A. and Rumelt, R.P., 1982. Uncertain imitability: An analysis of interfirm differences in efficiency under competition. Bell Journal of Economics 13, 418438.

Love, J.F., 1995. Mcdonald's: Behind the Arches. Rev. ed. Bantam Books, New York.

Luo, Y., 2000. Determinants of local responsiveness: Perspectives from foreign subsidiaries in an emerging market. Journal of Management 27, 451-477.

McNamara, P. and Baden-Fuller, C., 2007. Shareholder returns and the explorationexploitation dilemma: R\&D announcements by biotechnology firms. Research Policy 36, 548-565.

Minkler, A.P., 1992. Why firms franchise: A search cost theory. Journal of Institutional and Theoretical Economics 148, 240-259.

Morosini, P., Shane, S. and Singh, H., 1998. National cultural distance and cross-border acquisition performance. Journal of International Business Studies 29, 137-158.

Nelson, R. and Winter, S., 1982. An Evolutionary Theory of Economic Change. Belknap Press, Cambridge.

Nohria, N. and Ghoshal, S., 1997. The Differentiated Network. Jossey-Bass Publishers, San Francisco.

Porter, M.E., 1996. What is strategy? Harvard Business Review 61-157.

Prahalad, C.K. and Doz, Y.L., 1987. The Multinational Mission: Balancing Local Demands and Global Vision. Free Press, New York.

Rivkin, J.W., 2000. Imitation of complex strategies. Management Science 46, 824-844.

Rivkin, J.W., 2001. Reproducing knowledge: Replication without imitation at moderate complexity. Organization Science 12, 274-293. 
Rosenzweig, P.M. and Nohria, N., 1994. Influences on human resource management practices in multinational corporations. Journal of International Business Studies 25, 229-251.

Schumpeter, J., 1911. The Theory of Economic Development. Harvard University Press, Cambridge, MA.

Siggelkow, N., 2002. Evolution toward fit. Administrative Science Quarterly 47, 125159.

Sorge, A., 1991. Strategic fit and the societal effect: Interpreting cross-national comparisons of technology, organization and human resources. Organization Studies 12, 161-190.

Szulanski, G. and Jensen, R.J., 2006. Presumptive adaptation and the effectiveness of knowledge transfer. Strategic Management Journal 27, 937-957.

Teece, D.J., Pisano, G. and Shuen, A., 1997. Dynamic capabilities and strategic management. Strategic Management Journal 18, 509-533.

Westney, D.E., 1987. Imitation and Innovation: The Transfer of Western Organizational Patterns to Meiji Japan. 1st ed. Harvard University Press, Cambridge, MA.

Westney, D.E., 1993. Institutional theory and the multinational corporation, in: Ghoshal, S. and Westney, D.E. (Eds.), Organization Theory and the Multinational Corporation. St. Martin's Press, New York, pp 53-76.

Westphal, J.D., Gulati, R. and Shortell, S.M., 1997. Customization or conformity? An institutional and network perspective on the content and consequences of TQM adoption. Administrative Science Quarterly 42, 366-394.

Winter, S.G., 1987. Knowledge and competence as strategic assets, in: Teece, D. (Ed.) The Competitive Challenge-Strategies for Industrial Innovation and Renewal. Ballinger, Cambridge, MA, pp 159-184.

Winter, S.G., 1995. Four Rs of profitability: Rents, resources, routines and replication, in: Montgomery, C.A. (Ed.) Resource-Based and Evolutionary Theories of the Firm: Towards a Synthesis. Kluwer Academic Publishers, Norwell, MA, pp 147-178.

Winter, S.G. and Szulanski, G., 2001. Replication as strategy. Organization Science 12, 730-743.

Yip, G.S., 1991. A performance comparison of continental and national businesses in Europe. Journal of International Marketing Review 8, 31-39.

Zaheer, S., 1995. Overcoming the liability of foreignness. Academy of Management Journal 38, 341-363.

Zahra, S.A. and George, G., 2002. Absorptive capacity: A review, reconceptualization, and extension. Academy of Management Review 27, 185-203. 